\title{
PESQUISA DE FATORES DE RISCO PARA A BRUCELOSE HUMANA ASSOCIADOS À PRESENÇA DE BRUCELOSE BOVINA NO MUNICÍPIO DE CORRENTES, ESTADO DE PERNAMBUCO, BRASIL
}

\section{T.G.S. Tenório' ${ }^{1}$, L.E.H. Melo' ${ }^{2}$ R.A. Mota ${ }^{2}$, C.H.C. Fernandes ${ }^{3}$, L.M. Sá2 ${ }^{2}$ R.J.C. Souto² ${ }^{2}$ J.W. Pinheiro Júnior ${ }^{4}$}

1Universidade Federal do Maranhão, Centro de Ciências Agrárias e Ambientais, MA - 230, km 4, s/no, CEP 65500-000, Chapadinha, MA, Brasil. E-mail: tacianagalba@yahoo.com.br

\section{RESUMO}

\begin{abstract}
Objetivou-se com este estudo investigar a presença de anticorpos anti-Brucella abortus em grupos ocupacionais envolvidos com a criação de bovinos no Município de Correntes, Estado de Pernambuco, avaliando-se os fatores de risco associados à infecção em humanos, e estimar a prevalência em rebanhos bovinos leiteiros. Para tanto, foram colhidas 1.089 amostras de bovinos adultos e de 56 pessoas e examinadas pelo teste do antígeno acidificado tamponado (AAT). As amostras humanas foram submetidas à soroaglutinação lenta em tubos (SAL) e ao 2-mercaptoetanol (2-ME) e, quando reagentes a uma ou ambas as técnicas, para qualquer título, foram examinadas pela técnica de fixação do complemento (FC). Adicionalmente, pessoas submetidas à colheita de sangue foram solicitadas a responder um questionário investigativo. A prevalência para bovinos foi de 6,8\% (74/1.089) obtidas através da SAL e 2-ME, e em humanos de 1,8\% (1/56) ao AAT. Na SAL foi observada positividade em 21,4\% (12/56) das amostras humanas, não havendo, entretanto, amostras reagentes ao 2-ME $(0 \%-0 / 12)$ e ao FC $(0 \%-0 / 12)$. Os fatores de risco estudados: consumo de leite cru e seus derivados, contato com secreções, manipulação de carnes, uso de luvas e transmissão iatrogênica na manipulação de vacina B19 não foram analisados estatisticamente, pois não se detectou nenhum indivíduo positivo ao teste de fixação do complemento. Os resultados deste estudo sugerem que a população da zona rural do Município de Correntes, PE, encontra-se exposta à infecção por $B$. abortus, embora não se possa inferir a existência de intercorrência entre a infecção bovina e a humana. De qualquer forma uma vigilância maior por parte das autoridades sanitárias deve ser implementada.
\end{abstract}

PALAVRAS-CHAVE: Brucelose bovina, brucelose humana, fator de risco, Correntes, Pernambuco.

\section{ABSTRACT}

RISK FACTORS FOR HUMAN BRUCELLOSIS ASSOCIATED WITH THE PRESENCE OF BOVINE BRUCELLOSIS IN CORRENTES COUNTY, STATE OF PERNAMBUCO, BRAZIL. The objective of this study was to investigate the presence of anti-Brucella abortus antibodies in occupational groups involved in cattle raising in Correntes County, Pernambuco State, Brazil, evaluating the risk factors associated with the infection in humans, and estimating the prevalence in dairy cattle. In order to do so, 1089 samples from adult bovines and from 56 humans were collected and examined by the tampon acidified antigen (TAA) test. The samples were subjected to slow serum agglutination (SSA) and to 2-mercaptoethanol (2-ME) and, when positive by one or both techniques, for any titer, were examined by the complement fixation (CF) technique. Additionally, people who were subjected to blood collection were asked to answer an investigative questionnaire. The prevalence for the bovines was $6.8 \%(74 / 1.089)$ obtained through the SSA and $2-\mathrm{ME}$, and in humans it was $1.8 \%(1 / 56)$ by TAA. In the SSA, $21.4 \%(12 / 56)$ of the human samples were positive, with, however, no samples positive by $2-\mathrm{ME}(0 \%-0 / 12)$ or by $\mathrm{CF}(0 \%-0 / 12)$. The studied risk factors: intake of raw milk and its byproducts, contact with secretion, meat manipulation, glove utilization and iatrogenic transmission in the handling of the B19 vaccine, were not analyzed statistically, because no individual was detected positive by the complement fixation test. The

${ }^{2}$ Universidade Federal Rural de Pernambuco, Departamento de Medicina Veterinária, Recife, PE, Brasil. ${ }^{3}$ UNITINS AGRO, Palmas, Tocantins, Brasil.

${ }^{4}$ Universidade Federal Rural de Pernambuco, Unidade Acadêmica de Garanhuns, Garanhuns, PE, Brasil. 
results of this study suggest that the population of the rural zone in Correntes County is exposed to infection by Brucella abortus, although it is not possible to infer the existence of intercurrence between the bovine and human infection. Nevertheless, greater vigilance by the health authorities must be implemented.

KEYWORDS: Bovine brucellosis, human brucellosis, risk factor, Correntes County, Pernambuco.

\section{INTRODUÇÃO}

A brucelose ainda é uma das zoonoses mais importantes e difundidas no mundo de acordo com a Food and Agriculture Organization (FAO), a Organização Mundial de Saúde (OMS) e a Organização Mundial de Saúde Animal (OIE) (Poesteret al., 2002).

O primeiro caso de brucelose humana foi descrito no Brasil em 1913 por Gonçalves Carneiro (VERONESI, 1976). GARCIA-CARRILHo (1987) descreveu um grande número de publicações sobre a doença entre 1930 e 1950, sendo esses casos atribuídos a grupos ocupacionais, principalmente, como magarefes e trabalhadores envolvidos com o processamento de carnes. Na espécie humana, a brucelose é considerada uma antropozoonose e uma doença ocupacional (Doganay; Aygen, 2003).

A incidência da doença no homemé pouco conhecida (CORBELL, 1997). Em contrapartida, sua susceptibilidade ao agente etiológico tem relevante importância, pois a Organização Mundial deSaúdeestima que a cada ano surjam 500 mil novos casos, afetando principalmente pessoas envolvidas com a bovinocultura (BRASIL, 2006; PAPPAS et al., 2006).

As espécies de Brucella melitensis, Brucella suis, Brucella abortuse Brucella canis apresentamimportância clínico-epidemiológicaesãoconsideradas patogênicas parahumanos (Young, 1995; CORBELL, 1997). A brucelose humana éendêmica em vários países do Mediterrâneo, Oriente Médio, Ásia, África e América do Sul, e alguns países da Europa como Grécia, Portugal, Espanha, Itália e França (MAURIN, 2005).

No Brasil, as informações, embora escassas, dão conta da ocorrência da brucelose em humanos, de acordo com estudos soroepidemiológicos realizados em diversas partes do país e em diferentes grupos ocupacionais, como fazendeiros, vaqueiros, médicos veterinários efuncionários de matadouro, constando ainda avaliações sobre os fatores de risco envolvidos.

Na região norte, LOPES (1999) realizou uma avaliação soroepidemiológica para brucelose em animais e humanos de alguns municípios do Estado do Pará, utilizando testes de ELISA com $32 \%$ (16/50) dehumanos sororreagentes para brucelose, onde estes mantinham contato com bovinos.

$\mathrm{Na}$ região centro-oeste, em um estudo realizado com trabalhadores rurais do Município de Araputanga, $\mathrm{MT}$, avaliou-se osfatores derisco associados à ocorrência de brucelose em 2,9\% (5/189) de indivíduos reagentes para Brucella abortus (SCHEIN, 2006).
Na região sul, GonçALVES et al. (2006) observaram 0,66\% (1/150) de indivíduos positivos para brucelose em um frigorífico no Estado do Paraná.

Na região sudeste, VASCONCELOS (2003) realizou um estudo para conhecer o perfil sorológico de estudantes, residentes e pós-graduados de medicina veterinária, incluindo a pesquisa de anticorpos anti- $B$. abortus, não identificando nenhuma amostra reagente na população estudada.

Na região nordeste, LACERDA et al. (2000) observaram 10,17\% (6/59) de magarefes em dois matadouros do Município de São Luis, MA. Em Pernambuco, no Município de Garanhuns, MendonçA (1997) encontrou 2,99\% de indivíduos positivos, utilizando a técnica do antígeno acidificado tamponado para pesquisa de B. abortus de vários grupos ocupacionais, dentre eles trabalhadores de mercado de carne, pecuaristas, tratadores de animais e estudantes de medicina veterinária.

Portanto, em qualquer contexto clínicoepidemiológico, o principal fator de risco da brucelose humana é a ocorrência primária da doença nos animais, especialmente envolvendo a espécie bovina. Sua gênese encontra-se estreitamente associada ao manejo das criações, ocorrendo com maior proporção nos rebanhos leiteiros submetidos a constantes renovações do plantel e com menor grau nos sistemas de criação fechados (RADOsTits et al., 2002).

Na região nordeste, constatou-se positividade à brucelose em bovinos de vários rebanhos dos Estados de Alagoas (Nunes, 2001), Rio Grande do Norte (Souza et al., 1999), Paraíba (Alves et al., 1991; Leite et al., 2003) e Pernambuco (Almeida et al., 2000; Silva et al., 2000; Silva, 2003; TENÓRIO et al., 2005).

Em geral, a transmissão da infecção animal é potencializada para as pessoas em decorrência da inobservância de normas adequadas no manejo sanitário das criações e de práticas insalubres das pessoas na lida sistemática com o gado bovino. A maior dificuldade de identificar e caracterizar a dinâmica da infecção em humanos é a inexistência de uma técnica específica para esse fim, sendo, por isso, utilizados nos ensaios sorológicos envolvendo pessoas, os mesmos testes de referência empregados para o diagnóstico da brucelose bovina, contidos no Programa Nacional de Controle e Erradicação da Brucelose e Tuberculose - PNCEBT, implementado pelo Ministério da Agricultura, Pecuária e Abastecimento - MAPA (BRASIL, 2004). 
Diante do exposto, este estudo teve como objetivo investigar a presença de anticorpos anti-B. abortus em grupos ocupacionais envolvidos com a criação de bovinos no Município de Correntes, Estado dePernambuco, avaliando-seosfatores deriscoassociadosàinfecçãoem humanos, com ênfase na brucelose bovina, e estimar a prevalência em rebanhos bovinos leiteiros.

\section{MATERIAL E MÉTODOS}

O estudo foi realizado no Município de Correntes que possui uma população de 17.044 habitantes e se localiza na microrregião de Garanhuns, mesorregião do Agreste Pernambucano (IBGE, 2000), nas seguintes coordenadas geográficas: $9^{\circ} 7^{\prime} 44^{\prime \prime}$ latitude sul e 36 $19^{\prime} 49^{\prime \prime}$ longitude oeste, a $391 \mathrm{~m}$ de altitude e apresentado uma área de $339 \mathrm{~m}^{2}$ e distanciando-se $281 \mathrm{~km}$ de Recife.

Foi determinada a soroprevalência de brucelose por B. abortus em amostras bovinas e a freqüência em amostras humanas em um mesmo ambiente agropecuário.

As amostras humanas foram colhidas por um técnico de enfermagem, sendo definido em função da disponibilidade voluntária das pessoas em doar sangue, após prévia explicação sobre o trabalho e o devido consentimento.

Para a determinação do número de amostras bovinas a serem testadas e da prevalência da brucelose foram usados ensaios de amostragem relacionados ao estudo de prevalência de enfermidades infecciosas crônicas preconizados por Astudillo (1979), em função de alguns critérios epidemiológicos, como tipo de exploração, categoria animal e a área geográfica:

a) número mínimo de amostras:

$$
\mathrm{n}^{\prime}=\frac{\mathrm{p}(100-\mathrm{p}) \mathrm{g}^{2}}{(\mathrm{p} \alpha / 100)^{2}}
$$

Onde: $\mathrm{p}=$ prevalência esperada da brucelose; $\mathrm{g}=$ fator determinante do grau de confiança $(1,962 \cong 4) \mathrm{e}$ $\alpha=$ margem de erro admissível. Desta forma, $\mathrm{n}^{\prime} \cong 1.076$ amostras.

b) prevalência da Brucelose Bovina:

Com base em resultados regionais (Almeida et al., 2000; Silva et al., 2000; TÉNÓRIO et al., 2005) foi definido $8,5 \%$ como prevalência esperada para a brucelose bovina, admitindo-se uma margem de erro de $20 \%$, com um grau de confiança de $95 \%$. A prevalência da brucelose, globalizada e por rebanho, foi estabelecida pela fórmula:

$$
\mathrm{p}=\frac{\mathrm{nr} .100 \%}{\mathrm{n}^{\prime}(\mathrm{ou} \mathrm{n})}
$$

Onde: $\mathrm{p}=$ prevalência esperada da brucelose; $\mathrm{nr}=$ número de amostras que reagiram positivamente na população examinada; $\mathrm{n}^{\prime}=$ número total de amostras testadas dos 28 rebanhos; $\mathrm{n}=$ número de amostras testados no rebanho.

Foram colhidas, nas 28 propriedades estudadas, amostras sanguíneas de todas as fêmeas com idade igual ou superior a 24 meses e em lactação, das que possuíram mais de 30 dias de parição e não vacinadas. As propriedades encontravam-se distribuídas nas cinco áreas abrangidas pelo Programa de Saúde da Família (PSF), vinculado ao Ministério da Saúde, e foramestabelecidas pelaSecretariaMunicipaldeSaúde de Correntes. Neste estudo utilizou-se uma amostragem por conveniência para a seleção das propriedades (REIS, 2003).

De cada doador, animal ou humano foram colhidos 5,0 mL de sangue através de venopunção com material descartável estéril, sendo esse material devidamenteidentificado, acondicionado encaminhado ao laboratório. Após a retração do coágulo em temperatura ambiente, as amostras foram centrifugadas por 10 minutos com força real de centrifugação igual a 5000G e, em seguida, o soro obtido foi acondicionado em tubos do tipo microtubos e armazenados a uma temperatura de $-18^{\circ} \mathrm{C}$ para posterior análise.

As amostras de ambas as espécies foram examinadas pelo teste do antígeno acidificado tamponado ${ }^{1}$ (AAT) utilizando-se antígeno produzido pelo Instituto de Tecnologia do Paraná - TECPAR, adquiridos na Superintendência Federal da Agricultura no Estado de Pernambuco, Ministério da Agricultura Pecuária e Abastecimento, sendo as humanas submetidas, também, à soroaglutinação lenta em tubos (SAL) e ao 2-mercaptoetanol (2-ME). Nos casos de reação aoSAL e/ ou 2-ME, para qualquer título, as amostras humanas foram examinadas pela técnica de fixação do complemento (Alton et al., 1988). Para a espécie bovina, as amostras soropositivas ao AAT foram submetidas as técnicas de soroaglutinação lenta em tubos (SAL) 2-Mercaptoetanol (2-ME) nas diluições de 1:25, 1:50, 1:100 e 1:200. A interpretação dos resultados foi realizada mediante a legislação em vigor (BRASIL, 2004).

As análises sorológicas foram realizadas nos Laboratórios de Pesquisa em Clínica de Grandes Animais e de Doenças Infecciosas do Departamento de Medicina Veterinária da Universidade Federal Rural de Pernambuco - UFRPE e no Laboratório Nacional Agropecuário, Recife (LANAGRO-PE), seguindo-se

${ }^{1}$ TECPAR - Lote: 002/05 - 003/05. 
as normas técnicas contidas no Programa Nacional de Controlee Erradicação da Brucelose e Tuberculose (BRASIL, 2004).

Com o objetivo de caracterizar os fatores de risco associados a possível conexão da infecção entre ambas as espécies, solicitou-se às pessoas que haviam sido submetidas à colheita de sangue que respondessem a um questionário investigativo contendo perguntas fechadas e aplicadas por uma única pessoa previamente treinada. Este foi dividido em três partes distintas: identificação, aspectos clínicos e aspectos gerais: consumo de leite cru; consumo de derivados de leite sem tratamento térmico (queijo coalho); contato com carne; contato com secreções como descargas vaginais, fetos abortados e placentas; contato com a vacina B19 e uso de luvas para manipulação dos animais de fetos e palpação retal.

As informações obtidas foram inseridas em um formulário eletrônico elaborado no programa Microsoft Access ${ }^{\circledR}$ e Visual Basic ${ }^{\circledR}$ para posterior tabulação dos dados e análise.

O estudo dos fatores de risco não foi estatisticamente analisado, pois não se detectou nenhuma pessoa positiva ao teste de fixação de complemento.

\section{RESULTADOS E DISCUSSÃO}

Dos 56 indivíduos examinados, (49 - Vaqueiros; 2 - Administradores; 3 - Estudantes; 1 - Médico Veterinário;1-Pecuarista), 1/56(1,8\%) apresentou anticorpos anti-B. abortus, ao teste do AAT. Subseqüentemente, $21,4 \%(12 / 56)$ reagiram a SAL, com títulos variando entre 1:25 e 1:50, porém nenhum reagiu ao 2-ME, com destaque para uma amostra que reagiu ao AAT e não apresentou reação deaglutinação aoSALeao 2-ME. As 13 amostras reagentes ao AAT (1) ou a SAL (12) foram submetidas à Fixação do Complemento, e não apresentaram positividade (Tabela 1).

Apesar da provável ocorrência da infecção por $B$. abortus em humanos em algumas regiões do Brasil Norte (Lopes, 1999), Centro-Oeste (SCHEIN, 2006), Sul (GonçALVEs et al., 2006) e Nordeste (MENDONÇA, 1997; LACERDA et al., 2000), este estudo não ratificou positividade de amostras. Portanto, os achados foram compatíveis com os obtidos na região sudeste (VASCONCELOS, 2003), onde não se identificou amostra reagente na população de estudantes, residentes e pós-graduados de medicina veterinária. Entretanto, diferiu de outros ensaios sorológicos realizados no Nordeste, que permitiramidentificar em Pernambuco 2,99\% (5/167) de prevalência entre trabalhadores de mercado de carne, pecuaristas, tratadores de animais e estudantes de medicina veterinária (MENDONÇA, 1997) e no Maranhão 10,17\% (6/59) (LACERDA et al., 2000).
Tabela 1 - Freqüência de humanos sororreagentes aos exame sorológicos para pesquisa de B. abortus, realizado pela técnica do AAT, SAL, 2-ME e FC no Município de Correntes, PE, Brasil.

\begin{tabular}{llcr}
\hline $\begin{array}{l}\text { Exames } \\
\text { sorológicos }\end{array}$ & Resultado & Amostras & $\begin{array}{c}\text { Freqüência } \\
(\%)\end{array}$ \\
\hline AAT & Reagente & 01 & 1,8 \\
& Não Reagente & 55 & 98,2 \\
Total & & 56 & 100,0 \\
SAL & Reagente & 12 & 21,4 \\
& Não Reagente & 44 & 78,6 \\
Total & & 56 & 100,0 \\
2-ME & Reagente & 0 & 0,0 \\
& Não Reagente & 56 & 100,0 \\
Total & & 56 & 100,0 \\
FC & Reagente & 0 & 0,0 \\
& Não Reagente & 12 & 100,0 \\
\hline Total & & 12 & 100,0 \\
\hline
\end{tabular}

Em relação à discrepância de resultados entre os três testes realizados e com base nos princípios técnico-científicos aplicados na interpretação de resultados relativos à brucelose bovina (PAUlin; FerreiraNeto, 2003; BRASIL 2004), devido à falta de técnicas específicas para a espécie humana, a positividade observada em 13 das amostras examinadas pode ser interpretada de diferentes formas: na amostra positiva ao AAT, sem a devida confirmação nos demais testes, o resultado deve ser interpretado como reação inespecífica, pois a imunoglobulina G dotipo1(IgG1), supostamente detectada, deveria obrigatoriamente ter sido identificada nos demais testes.

Nesse sentido, é preciso destacar que reações inespecíficas podem ocorrer nesses testes devido a bactérias que podem interferir e promover reações falso-positivas no diagnóstico da brucelose animal e humana, sendo mencionadas a Yersiniaenterocolitica, Escherichia coli e Francisella tularensis (FERrAz, 1999; Paulin; Ferreira Neto, 2003; Hirsh; Zee, 2003).

As reações observadas nas outras 12 amostras examinadas na SAL, negativas no AAT, 2-ME e fixação de complemento, devem ser interpretadas, como resultados negativos (BRASIL, 2004). Todavia, podem representar reações inespecíficas, ou ainda, reações compatíveis com infecção incipiente por B. abortus (GAZAPO, 1989; ArIZA, 1992). Neste caso, deve-se ressaltar ofato daSAL ter a propriedade de detectar mais imunoglobulina M (IgM) do que IgG, inclusive em títulos maiores do que o teste de fixação de complemento.

Das 1.089 amostras bovinas examinadas, nos 28 rebanhos leiteiros, 84 reagiram positivamenteao AAT e 74 foram confirmadas ao 2-ME, onde 10 amostras apresentaram resultado inconclusivo na técnica do 
SAL e foram excluídas dos cálculos. A prevalência da brucelose foi estimada em 6,8\% (74/1089), variando a um intervalo de $5,3 \%$ a $8,3 \%$ (Tabela 2).

Tabela 2 - Distribuição de bovinos portadores de anticorpos anti-B. abortus, segundo as propriedades estudadas no Município de Correntes, PE, Brasil.

\begin{tabular}{|c|c|c|c|}
\hline Rebanhos & Positivos (\%) & Negativos (\%) & Total \\
\hline $\mathrm{R} 1$ & $4(23,5)$ & $13(76,5)$ & 17 \\
\hline $\mathrm{R} 2$ & $1(7,7)$ & $12(92,3)$ & 13 \\
\hline R3 & $2(7,1)$ & $26(92,9)$ & 28 \\
\hline $\mathrm{R} 4$ & $0(0,0)$ & $42(100,0)$ & 42 \\
\hline R5 & $5(4,5)$ & $105(95,5)$ & 110 \\
\hline R6 & $0(0,0)$ & $20(100,0)$ & 20 \\
\hline R7 & $0(0,0)$ & $13(100,0)$ & 13 \\
\hline R8 & $6(19,4)$ & $25(80,6)$ & 31 \\
\hline R9 & $0(0,0)$ & $93(100,0)$ & 93 \\
\hline R10 & $1(2,6)$ & $38(97,4)$ & 39 \\
\hline R11 & $0(0,0)$ & $14(100,0)$ & 14 \\
\hline $\mathrm{R} 12$ & $0(0,0)$ & $23(100,0)$ & 23 \\
\hline R13 & $5(8,0)$ & $57(92,0)$ & 62 \\
\hline R14 & $1(9,0)$ & $10(91,0)$ & 11 \\
\hline R15 & $3(15,0)$ & $17(85,0)$ & 20 \\
\hline R16 & $0(0,0)$ & $13(100,0)$ & 13 \\
\hline R17 & $3(21,4)$ & $11(78,6)$ & 14 \\
\hline R18 & $3(2,2)$ & $133(97,8)$ & 136 \\
\hline R19 & $0(0,0)$ & $42(100,0)$ & 42 \\
\hline $\mathrm{R} 20$ & $0(0,0)$ & $19(100,0)$ & 19 \\
\hline $\mathrm{R} 21$ & $8(16,0)$ & $42(84,0)$ & 50 \\
\hline R22 & $7(27,0)$ & $19(73,0)$ & 26 \\
\hline R23 & $6(14,6)$ & $35(85,4)$ & 41 \\
\hline R24 & $2(5,9)$ & $32(94,1)$ & 34 \\
\hline R25 & $3(6,0)$ & $47(94,0)$ & 50 \\
\hline R26 & $16(22,2)$ & $56(77,8)$ & 72 \\
\hline $\mathrm{R} 27$ & $3(6,0)$ & $34(00,0)$ & 37 \\
\hline $\mathrm{R} 28$ & $0(0,0)$ & $15(00,0)$ & 15 \\
\hline Total & $74(6,8)$ & $1.015(93,2)$ & 1.089 \\
\hline
\end{tabular}

Esse achado foi equivalente ao de levantamentos anteriores realizados em Pernambuco (SILVA et al., 2000; Silva, 2003; Tenórioet al., 2005), Alagoas (NunES, 2001), Rio Grande do Norte (Souza et al., 1999) e Paraíba (Alves et al., 1991; Leite et al., 2003). Entretanto, foi inferior aos $19,3 \%$ de positividade detectados por AlmeIDA et al. (2000) em 150 amostras procedentes de vacas do Município de Sanharó, PE. A brucelose bovina mantém-se nos rebanhos leiteiros de Pernambuco, todavia, sua prevalência alta, ainda que recrudescente, deve-se aos efeitos negativos de um conjunto de ações sanitárias oficiais implementadas ao longo das últimas décadas em praticamente todas as regiões do país.
Os resultados obtidos neste estudo não comprovaram o caráter zoonótico da brucelose bovina reconhecido universalmente (ACHA;SZIFRES, 2001). Entretanto, é significante a presença da brucelose bovina na população examinada, onde $64,3 \%(18 / 28)$ das propriedades apresentaram animais positivos, com uma prevalência da infecção de 6,8\% (74/1.089). Além do seu recrudescimento, ao se comparar os achados a trabalhos anteriores (TeNório et al., 2005), cria uma situação potencialmente crítica, com a coexistência de fatores que colocam em risco a saúde das pessoas que convivem no ambiente agropecuário estudado.

Em relação à investigação dos possíveis fatores de risco da transmissão da brucelose bovina para as pessoas envolvidas neste estudo, depreende-se que a maioria delas encontrava-se exposta ao agente etiológico da brucelose bovina.

Neste sentido, 78,6\% (44/56) das pessoas consumiam leite crue $89,3 \%(50 / 56)$ delas os seus derivados sem tratamento térmico, principalmente o queijo coalho. Esta é uma real exposição, uma vez que constitui uma via importante de transmissão de Brucella sp. (LANGONi et al., 2000; Metin et al., 2001). Deve-se destacar que BotelHo etal. (2000) isolaram B. abortusnoleite de vacas infectadas na mesma região estudada.

Em relação ao contato com carne, 57,2\% (32/56) das pessoas encontrava-se sob este risco, embora se saiba que é de menor magnitude, quer o contato ou a ingestão de carnes, pela menor quantidade debrucelas encontradas nos linfonodos que pode estar impregnados na musculatura, além das temperaturas elevadas que as carnes são submetidas quando utilizadas na culinária tradicional (MARTINS, 1994).

Preocupante foi perceber que $73,2 \%(41 / 56)$ das pessoas mantinham, pela lida diária com gado bovino, constante contato com secreções (descargas vaginais, fetos abortados e placentas). Trata-se, certamente, do mais importante fator de risco à saúde das pessoas (VASCONCELOS, 2003), especialmente quando há registro de brucelose no rebanho bovino, dentre outras doenças da esfera reprodutiva.

As pessoas examinadas encontravam-se, quase sempre, em situações insalubres: $73,2 \%(41 / 56)$ delas nãofaziam uso doequipamento de proteção individual (EPI), estando expostas à infecção, podendo o risco ser caracterizado pelo contato direto de abrasões da pele com tecidos de animais infectados e por via respiratória pela inalação de aerossóis (CARTER; CHENGAPPA, 1991; CorrêA; CorrêA, 1992; FerraZ, 1999; Hirsh; ZeE, 2003; Doganay; Aygen, 2003; Franzolin, 2005).

\section{CONCLUSÃO}

A população da zona rural noMunicípio deCorrentes, $\mathrm{PE}$, Brasil,comênfaseaos grupos deriscoestudados, 
encontra-se exposta à infecção por B. abortus, com uma prevalência estimada de 6,8\% (74/1.089) em bovinos sororreagentes nos rebanhos leiteiros estudados nesta região embora não se possa inferir transmissibilidade da infecção entre as populações bovina e humana examinadas. De qualquer forma, uma vigilância maior por partedasautoridadessanitárias deveserimplementada.

\section{REFERÊNCIAS}

ACHA, P.N.; SZYFRES, B. Zoonosis y enfermedades transmisibles comunes al hombre y a los animales. 3.ed. Washington: Organización Panamericana de La Salud/ Oficina Sanitária Panamericana/Oficina Regional de la Organización Mundial de la Salud, 2001. v.1,398p.

ALMEIDA, H.J.O.; MOTA, R.A.; NASCIMENTO, S.A.; HARROP, M.H.V.; CASTRO, R.S.; CUNHA, E.J.G. Prevalência de bovinos sororreagentes para Brucella abortus, Leptospira interrogans e Vírus da diarréia viral bovina (BVDV) em bovinos do município de Sanharó PE. Ciência Veterinária nos Trópicos, v.3, n.2, p.93-101, 2000.

ALVES, C.J.; ALBUQUERQUE, A.X.; LEITE, E.A.; AZEVEDO, E.O. Situação soroepidemiológica da brucelose bovina na depressão de Patos - PB, no período de junho de 1991 a julho de 1992, Arquivos da Escola de Medicina Veterinária de Universidade Federal da Bahia, v.16, n.1, p.1-7, 1991.

ALTON, G.G.; JONES, L.M.; ANGUS, R.D.; VERGER, J.M. Techniques for the brucellosis laboratory. Paris: Institut National de la Recherche Agronomique, 1988. 190p.

ARIZA, J. Specific antibody profile in human brucellosis. Clinical Infection Diseases, v.14, n.1, p.131-140, 1992.

ASTUDILLO, V. M. Encuesta por muestra para estudios epidemiologicos en populaciones animals. Rio de Janeiro: Centro Panamericano de Febre Aftosa, 1979.60p. (Serie de Manuales Didáticos n. 12)

BOTELHO, A.P.; MOTA, R.A.; SILVA, L.B.G.; SANTOS FILHO, A.S.; COELHO, R.M.S.; LIMA, E.T. Recuperação de Brucella abortus do leite in natura procedente de vacas soropositivas dos municípios de Pedra e Venturosa - PE. Higiene Alimentar, v.11, n.73, p.72-78, 2000.

BRASIL. Ministério da Agricultura, Pecuária e Abastecimento. Departamento de Defesa Animal. Programa Nacional de Controle e Erradicação da Brucelose e Tuberculose (PNCEBT) -. Brasília: Departamento de Defesa Animal, 2004. 132p. (Manual Técnico)

BRASIL. Ministério da Saúde. Secretaria de Vigilância em Saúde. Departamento de Vigilância Epidemiológica. Doenças Infecciosas e Parasitárias: Guia de Bolso. 6.ed. Brasília: Ministério da Saúde, 2006. 320p.
CARTER, G.R.; CHENGAPPA, M.M. Brucella In: Essentials of veterinary

bacteriology and mycology. 4.ed. Philadelphia: London, 1991. cap. 24, p.106-201.

CORBELL, M.J. Brucellosis: an overview. In: INTERNATIONAL CONFERENCE ON EMERGING ZOONOSES, 1., Jerusalem, Israel. Emerging Infectious Diseases, v.3, n.2, p.213-221, 1997. Disponível em: <http://www.cdc.ncidod/eid/vol.3no2/corbel.htm>. Acesso em: 9 jan. 1998.

CORRÊA, W.M.; CORRÊA, C.N.M. Enfermidades infecciosas dos mamíferos domésticos. Rio de Janeiro: Medsi, 1992. p.843.

DOGANAY, M.; AYGEN, B. Humana brucellosis: an overview. International Journal of Infectious Diseases, v.7, n.3, p.173-182, 2003.

FERRAZ, I.B.F. Novos métodos de controle e diagnóstico da brucelose bovina. Revista Brasileira de Reprodução Animal, v.23, n.4, p.504-508, 1999.

FRANZOLIN, M.R. Brucella e Francisella. In: TRABULSI, L.R.; ALTERTHUM, F. (Ed.). Microbiologia. 4.ed. São Paulo: Atheneu, 2005. Cap. 33, p.261-263.

GARCIA-CARRILLO, C. La Brucelosis de los animales en America y su relacion con la infeccion humana. Paris: Office International des Epizooties, 1987. p.43-70.

GAZAPO, E. Changes in IgM and IgG antibody concentrations in Brucellosis overtime: importance for diagnosis and follow up. Journal Infection Diseases, v.159, n.2, p.219-225, 1989.

GONÇALVES, D.D.; TELES, P.S.; REIS, C.R.; LOPES, F.M.R.; FREIRE, RL.; NAVARRO, I.T.; ALVES, L.A.; MULLER, E.E.; FREITAS, J.C. Soroepidemiologia e variáveis ocupacionais e ambientais relacionadas à leptospirose, brucelose e toxoplasmose em trabalhadores de frigorífico do Estado do Paraná, Brasil. Revista do Instituto de Medicina Tropical de São Paulo, v.48, n.3, p.135-140, 2006.

HIRSH, D.C.; ZEE, Y.C. Microbiologia Veterinária. Rio de Janeiro: Guanabara Koogan, 2003. 446p.

INSTITUTO BRASILEIRO DE GEOGRAFIA E ESTATÍSTICA - IBGE. Censo Demográfico 2000. Brasil. Disponível em: <http:// www1.ibge.censodemografico.org.br/ populacao.asp>. Acesso em: 27 out. 2006.

LACERDA, L.M.; ALVES, L.M.C.; MATHIAS, L.A.; RODRIGUES, A.L.B.; ALMEIDA, F.M. Brucelose em trabalhadores de matadouros do município de São Luis, MA, 1997. Higiene Alimentar, v.14, n.68/69, p.62-65, 2000.

LANGONI, H.; ICHIHARA, S.M.; SILVA, A.V.; PARDO, R.B.; TONIN, F.B.; MENDONÇA, L.J.P.; MACHADO, 
J.A.D. Isolation of Brucella spp. From milk of brucellosis positive cows in São Paulo and Minas Gerais states. Brazilian Journal of Veterinary Research and Animal Science, v.37, n.6, p.444-448, 2000.

LEITE, R.M.H.; THOMPSON, J.A.; GONÇALVES, V.S.P.; LEITE, R.C.; BANDEIRA, D.A.; LAGE, A.P. A random sample survey of bovine brucellosis in the State of Paraíba, Brazil. Brazilian Journal of Veterinary Research and Animal Science, v.40, p.170-174, 2003. Suplemento.

LOPES, C.F.A. Avaliação soroepidmeiológica da brucelose em animais e humanos procedentes de alguns municípios do Estado do Pará-Brasil. 1999. 113 f. Dissertação (Mestrado) - Universidade Federal do Pará e Museu Paraense "Emílio Goeldi", Belém, 1999.

MARTINS, M.V.F.A. Brucella e os produtos alimentares de origem animal. Veterinária Técnica, n.2, p.20-23, 1994.

MAURIN, M. La brucellose à l'aube du $21^{\mathrm{e}}$ siècle. Médicine et Maladies Infectieuses, v.35, p.6-16, 2005.

MENDONÇA, C.A.S. Pesquisa de soropositividade para diagnostico de brucelose em grupos ocupacionais do município de Garanhuns-PE, submetidos às provas de soroaglutinação rápida (SAR) e Antígeno tamponado acidificado (ATA). In: CONGRESSO DE INICIAÇAO CIENTIFICA DA UFRPE, 7., 1997, Recife. Resumo. Recife: UFRPE, 1997, p.369.

METIN, A.AKDENIZ, H.; BUZGAN, T.; DELICE, I. Cutaneous findings encountered in brucellosis and review of the literature. International Journal of Dermatology, v.40, n. 7, p.434-438, 2001.

NUNES, A.C.B.T. Prevalência da Brucelose Bovina em Rebanhos Leiteiros da Microrregião de Batalha-AL. 2001, 37f. Dissertação (Mestrado em Ciência Veterinária) Universidade Federal Rural de Pernambuco, Recife, 2001.

PAPPAS, G.; PAPADIMITRIOU, P.; AKRITIDIS, N.; CHRISTOU, L.; TSIANOS, E.V. The new global map of human brucellosis. The Lancet Infectious Diseases, v.6, p.91-99, 2006. Disponível em: <http:/ /infection. thelancet.com>. Acesso em: 25 jul. 2006.

PAULIN, L.M.; FERREIRA NETO, J.S. O Combate à brucelose bovina. Situação Brasileira. Jaboticabal: FUNEP, 2003. 154p.

POESTER, F.P.; GONÇALVES, V.S.P.; LAGE, A.P. Brucellosis in Brazil. Veterinary Microbiology, v.90, p.5562,2002
RADOSTITS, O.M.; GAY, C.C.; BLOOD, D.C.; HINCHCLIFF, K.W. Clínica Veterinária - Um Tratado de Doenças dos Bovinos, Ovinos, Suínos, Caprinos e Eqüinos. 9.ed. Rio de Janeiro: Guanabara Koogan, 2002. 1737p.

REIS, J.C. Estatística aplicada à pesquisa em ciência veterinária. Recife: Copyright, 2003. 651 p.

SCHEIN, F.B. Prevalência de Brucelose no Rebanho Bovino Leiteiro e na Família Rural do Município de Araputanga MT. 2006. 87p. Dissertação (Mestrado) - Universidade Federal Rural de Pernambuco, Recife, 2006.

SILVA, L.B.G.; RABELO, S.S.A.; MOTA, R.A.;

GALINDO, R.C.G.; CUNHA, A.P.; NASCIMENTO

SOBRINHO, E.S. Pesquisa de Anticorpos Anti-Brucella em bovinos leiteiros do Município de Gravatá - PE (Resultados Preliminares). In: CONGRESSO BRASILEIRO DE MEDICINA VETERINÁRIA, 27., 2000, Águas de Lindóia. Resumo. Águas de Lindóia, 2000. p.74.

SILVA, M.I.S. Aspectos Epidemiológicos das infecções por Neospora caninum, Toxoplasma gondi, Brucella abortus e vírus da diarréia viral bovina em matrizes leiteiras do Município de Gravatá - PE. 2003. 81p. Tese (Doutorado) - Universidade Federal Rural de Pernambuco, Recife, 2003.

SOUZA, M.F.; LOPES, F.C.; AZEVEDO, E.O. Prevalência de Brucelose bovina em área de assentamento rural no município de Riachuelo - RN. In: CONGRESSO PERNAMBUCANO DE MEDICINA VETERINÁRIA, 4., 1999, Recife. Resumos. Recife: SPEMVE, 1999. p.261-262.

TENÓRIO, T.G.S.; MELO, L.E.H.; VASCONCELLOS, S.A.; CASTRO, R.S.; SILVA, F.F.; LEITE, J.E.B.; RÊGO, E.W.; VAZ, B.D.; BORBA, M.A.C.; MELO, M.T.; CASTRO, V.B.; CAMPOS, K.M.T.; BERTO, R.S.; MENDES, E.I. Soroprevalência da brucelose e leptospirose em de rebanhos bovinos leiteiros do Estado de Pernambuco. Veterinária Notícias, v.11, n.2, p.43-48, 2005.

VASCONCELOS, C.G.C. Zoonoses ocupacionais: inquérito soro-epidemiológico em estudantes de medicina veterinária, e análise de risco para Leptospirose, Brucelose e Toxoplamose. 2003. 108p. Tese (Doutorado) - Universidade Estadual Paulista, Botucatu, 2003.

VERONESI, R. Doenças infecciosas e parasitárias . 6.ed., Rio de Janeiro: Guanabara Koogan, 1976. p.421.

YOUNG, E.J. An overvien of human brucellosis. Clinical Infection Diseases, v.21, p.283-290, 1995.

Recebido em 26/5/07

Aceito em 18/11/08 